\title{
Design and Fabrication of $\mathrm{N}$-Alkyl-Polyethylenimine-Stabilized Iron Oxide Nanoclusters for Gene Delivery
}

\author{
Gang Liu ${ }^{*}, \dagger$, , Zhiyong Wang $\$$, Seulki Lee ${ }^{\dagger}$, Hua Ai ${ }^{\S}, 1$, and Xiaoyuan Chen ${ }^{*}, \dagger, 1$ \\ ${ }^{*}$ Center for Molecular Imaging and Translational Medicine, School of Public Health, Xiamen \\ University, Xiamen, China \\ †Laboratory of Molecular Imaging and Nanomedicine, National Institute of Biomedical Imaging \\ and Bioengineering, National Institutes of Health, Bethesda, Maryland, USA \\ ¥Sichuan Key Laboratory of Medical Imaging, North Sichuan Medical College, Nanchong, China \\ $\S$ National Engineering Research Center for Biomaterials, Sichuan University, Chengdu, China
}

\begin{abstract}
With the rapid development of nanotechnology, inorganic magnetic nanoparticles, especially iron oxide nanoparticles (IOs), have emerged as great vehicles for biomedical diagnostic and therapeutic applications. In order to rationally design IO-based gene delivery nanovectors, surface modification is essential and determines the loading and release of the gene of interest. Here we highlight the basic concepts and applications of nonviral gene delivery vehicles based on low molecular weight $N$-alkyl polyethylenimine-stabilized IOs. The experimental protocols related to these topics are described in this chapter.
\end{abstract}

\section{Introduction}

Magnetic nanoparticles, such as iron oxide nanoparticles (IOs), are an important class of nanomaterials with interesting properties (biocompatibility, magnetic properties, physical/ chemical stability, and low cost) that have been developed into various functional agents for applications in imaging, cell labeling, hyperthermia, and drug/gene delivery (Liu et al., 2010b, 2011a, c; Xie et al., 2011). To rationally design IO-based gene delivery nanovectors, surface modification processes are necessary to stabilize IOs to create strong interactions for binding of the therapeutic gene and to control the release mechanism (Hao et al., 2010; Liu et al., 2010a; Taratula et al., 2011; Veiseh et al., 2010). In addition, surface engineering can play a central role in determining the internalization rate and toxicity of the particles (Liu et al., 2009; Wang et al., 2009). A common strategy is to convert the IO surface to a polycation layer, onto which the highly negatively charged therapeutic gene can be electrostatically attracted and tethered. This is mostly achieved by introducing one layer of cationic polymers onto IO surfaces to design nonviral gene delivery vehicles (Arsianti et al., 2010; Cheong et al., 2009; Scherer et al., 2002).

Among many nonviral gene carriers, polyethylenimine (PEI) is one of the most effective gene delivery vehicles that can bind negatively charged nucleic acids via electrostatic interactions, protect nucleic acids from degradation by restriction of endonucleases, and enter cells through rapid endocytosis (Demeneix and Behr, 2005; Godbey et al., 1999). In addition, PEI is also able to delay the acidification and fusion of intracellular organelles

\footnotetext{
(C) 2012 Elsevier Inc. All rights reserved.

${ }^{1}$ Corresponding authors: huaai@scu.edu.cn; shawn.chen@nih.gov.
} 
through "proton sponge" effects, which cause osmotic swelling of endosomes and subsequent release of the trapped nucleic acid into the cytosol (Boussif et al., 1995; Demeneix and Behr, 2005). It is well known that the transfection efficiency and cytotoxicity of PEI correlate strongly with its molecular weight. High molecular weight PEI exhibits much higher transfection efficiency as well as cytotoxicity compared to its lower molecular weight analogues (Godbey et al., 1999). However, recent studies show that cross-linked low molecular weight PEI, or IO/gold nanoparticles "wrapped" in low molecular weight PEI, could enhance gene delivery efficiency without compromising its low cytotoxicity (Hu et al., 2010; Huang et al., 2010; Kievit et al., 2009; Liu et al., 2011d; Thomas and Klibanov, 2003). It is possible that the efficient unpacking of complexes and subsequent siRNA release from IOs, with its unique nanostructure, into the cytoplasm, contribute to an enhanced genesilencing effect when compared with $N$-alkyl-PEI2k/ siRNA complexes (Liu et al., 2011d). Here we describe an approach to form IO-siRNA complexes that can be used to monitor the transfection efficiency, as well as to track the cells in gene therapy applications.

\section{Materials}

\subsection{Reagents}

PEI2k (MW: 1.8 kD) (Alfa Asear); 1-iodododecane (Aldrich Chemical Co.); iron(III) acetylacetonate (Aldrich Chemical Co.); 1,2-hexadecanediol (Aldrich Chemical Co.); benzyl ether (Aldrich Chemical Co.); oleic acid (Aldrich Chemical Co.); oleylamine (Aldrich Chemical Co.); chloroform (Sigma); dimethyl sulfoxide (Sigma); heparin (Sigma); phosphate-buffered saline (PBS) (Gibco); RPMI 1640 medium (Invitrogen); fetal bovine serum (FBS) (Hyclone); TAE electrophoresis buffer (Gibco); ethidium bromide (Gibco); agarose gel (Gibco); L-glutamine (Mediatech, Inc.); penicillin-streptomycin (Mediatech, Inc.); streptomycin (Mediatech, Inc.); trypsin-EDTA (Mediatech, Inc.); D-luciferin (Gold Bio Technology, Inc.); 3-(4,5-dimethylthiazol-2-yl)-2,5-diphenyltetrazolium bromide (Sigma); firefly luciferase siRNA (Ambion); Lipofectamine 2000 (Invitrogen, Grand Island, NY, USA); plasmid DNA encoding firefly luciferase protein (System Biosciences); murine 4T1 breast cancer cell line (American Type Culture Collection (ATCC)); the 4T1 cell line stably expressing luciferase gene (4T1-fluc).

\subsection{Equipment}

1. Reaction vessel, magnetic stirrer, and magnetic rod

2. Thermal analysis instrument

3. Dialysis membranes

4. Freeze dry system

5. Nuclear magnetic resonance (NMR) spectrometer

6. Dynamic light scattering (DLS) and zeta potential instrument

7. Transmission electron microscope (TEM)

8. Atomic force microscopy (AFM)

9. Gel electrophoresis apparatus equipped with an image acquisition system

10. Controlled environment incubator $\left(37^{\circ} \mathrm{C}, 5 \% \mathrm{CO}_{2}\right)$ for cell culture

11. Pipettes, tips, and cell culture plates

12. Centrifuge and centrifuge tubes

13. Inverted microscope 
14. Cell counter

15. Fluorescence microplate reader

16. MR scanner and ImageJ software

17. Xenogen IVIS-100 system and Living Image v.3.1 software

\section{Methods}

\subsection{Fabrication of $\mathbf{N}$-alkyl-polyethylenimine-stabilized iron oxide nanocluster \\ 3.1.1. Synthesis of $\mathrm{N}$-alkyl-PEI2K}

1. 1-Iodododecane $(1 \mathrm{mmol})$ is added to dry PEI $(0.25 \mathrm{mmol})$ and dissolved in absolute ethanol $(10 \mathrm{ml})$ in a $50-\mathrm{ml}$ round-bottom flask.

2. Then, the container is put into liquid nitrogen. After the solution is converted into solid, the container is evacuated, put into argon, and heated to $55^{\circ} \mathrm{C}$ for $6 \mathrm{~h}$ with magnetic stirring.

3. After cooling to room temperature, the solution is incubated at room temperature overnight to remove the ethanol by rotary evaporation.

4. The crude product is dissolved in water, treated with $11 \mathrm{~mol} \%$ of $\mathrm{NaOH}$, and dialyzed in a dialysis bag extensively against water (molecular mass cutoff, $1 \mathrm{kDa}$ ) at room temperature.

5. The pure products are analyzed using ${ }^{1} \mathrm{H} \mathrm{NMR}\left(\mathrm{CDCl}_{3}\right)$.

\subsubsection{Synthesis of IOs}

1. $\mathrm{Fe}(\mathrm{acac})_{3}(1 \mathrm{mmol})$ is mixed with 1,2 -hexadecanediol $(5 \mathrm{mmol})$, oleic acid (3 $\mathrm{mmol})$, and oleylamine $(3 \mathrm{mmol})$ in benzyl ether $(10 \mathrm{ml})$ under nitrogen.

2. The mixture is heated to reflux $\left(300^{\circ} \mathrm{C}\right)$ for $1 \mathrm{~h}$.

3. After cooling to room temperature $\left(23^{\circ} \mathrm{C}\right)$, ethanol is used to yield a dark-brown precipitate from the solution.

4. The product is redispersed in hexane with oleic acid and oleylamine, and reprecipitated with ethanol to give $6 \mathrm{~nm} \mathrm{Fe}_{3} \mathrm{O}_{4}$ nanoparticles.

5. The $6 \mathrm{~nm} \mathrm{Fe}_{3} \mathrm{O}_{4}$ nanoparticles are used as seeds to synthesize $12 \mathrm{~nm} \mathrm{Fe} \mathrm{O}_{4}$ nanoparticles.

5.1 $\mathrm{Fe}(\mathrm{acac})_{3}(1 \mathrm{mmol})$ is mixed with 1,2-hexadecanediol (5 mmol), benzyl ether $(10 \mathrm{ml})$, oleic acid $(1 \mathrm{mmol})$, oleylamine $(1 \mathrm{mmol})$, and $6 \mathrm{~nm}$ $\mathrm{Fe}_{3} \mathrm{O}_{4}$ nanoparticles $(41 \mathrm{mg}$ ) dissolved in hexane.

5.2 The mixture is heated to $100{ }^{\circ} \mathrm{C}$ for $30 \mathrm{~min}$ to remove hexane.

5.3 The mixture is heated to $300{ }^{\circ} \mathrm{C}$ to reflux for $30 \mathrm{~min}$. After cooling to room temperature $\left(23^{\circ} \mathrm{C}\right)$, ethanol is used to yield a dark-brown precipitate from the solution.

5.4 The product is redispersed in hexane with oleic acid and oleylamine, and reprecipitated with ethanol to give $12 \mathrm{~nm} \mathrm{Fe}_{3} \mathrm{O}_{4}$ nanoparticles.

6. The SPIO nanocrystals are analyzed by DLS and TEM. 


\subsubsection{Preparation of $\mathbf{N}$-alkyl-PEI2K-IO nanoparticles}

1. The SPIO nanoparticles $(5 \mathrm{mg})$ are redispersed in $1 \mathrm{ml}$ chloroform, together with $N$-alkyl-PEI2K (3 mg).

2. The above solution is added to $10 \mathrm{ml}$ water with probe sonication (VCX130; Sonic $\&$ Materials Inc.) at room temperature.

3. The solution is mixed by shaking for $24 \mathrm{~h}$, and the remaining chloroform is removed by rotary evaporation.

4. The composition of $N$-alkyl-PEI2K-IOs is determined via thermogravimetry analysis (TGA) on a NETZSCH Thermal Analysis Instrument at a heating rate of $10{ }^{\circ} \mathrm{C} /$ min from $35^{\circ} \mathrm{C}$ to $1000{ }^{\circ} \mathrm{C}$, under a $\mathrm{N}_{2}$ atmosphere.

5. The size and morphology are established through DLS, zeta potential, AFM, and TEM analysis.

6. The $T_{2}$ relaxivity is determined at $3 \mathrm{~T}$ on a clinical MR scanner (Siemens Sonata): $\mathrm{TR}=5000 \mathrm{~ms}$, TE values ranging from 6 to $170 \mathrm{~ms}$.

7. The $r_{2}$ relaxivity is calculated through the curve fitting of $1 /$ relaxation time $\left(\mathrm{s}^{-1}\right)$ versus the iron concentration ( $\mathrm{mM} \mathrm{Fe}$ ).

\subsection{N-alkyl-PEI2K-SPIO-siRNA complex formation and properties}

1. For the binding assay, an appropriate amount of $N$-alkyl-PEI2k-IOs is added to the siRNA solution (6 pmol) with different N/P ratios (i.e., N/P ratio from 5 to 50 ).

2. The mixed solutions are incubated at room temperature for 20-30 min to allow for the formation of IO-siRNA complexes.

3. The IO-siRNA complexes are characterized by DLS and zeta potential measurements.

4. The IO-siRNA complexes are loaded onto a $2 \%$ agarose gel with ethidium bromide $(0.5 \mu \mathrm{g} / \mathrm{ml})$ for visualization.

5. The electrophoresis is run at $100 \mathrm{~V}$ for $15 \mathrm{~min}$.

6. The gel is placed on top of a UV transilluminator (Sigma-Aldrich) to observe the migration of the IO-siRNA complexes within the agarose gel.

7. For the siRNA release assay, the IO-siRNA complexes are mixed at the fullbinding ratio (N/P ratio 20:1) with varying amounts of heparin and incubated for approximately $10 \mathrm{~min}$.

8. The above solution is loaded into the agarose gel, and the electrophoresis is run at $100 \mathrm{~V}$ for $15 \mathrm{~min}$.

9. The IO-siRNA complexes and the dissociated siRNA are detected as described above.

10. For serum stability assay, IO-siRNA complexes (N/P ratio 20:1) are incubated with serum (final $50 \%$ concentration) at $37^{\circ} \mathrm{C}$.

11. After incubation for $24 \mathrm{~h}$, heparin $(10 \mu \mathrm{g})$ is added to the treated IO-siRNA complex samples.

12. The above solution is loaded into the agarose gel, and the electrophoresis is run at $100 \mathrm{~V}$ for $15 \mathrm{~min}$.

13. The IO-siRNA complexes and undegraded siRNA are detected as described above. 


\subsection{Cell transfection with IO-siRNA complexes}

1. $4 \mathrm{~T} 1$ cells stably expressing the luciferase gene (4T1-fluc) are cultured in RPMI 1640 medium supplemented with $10 \% \mathrm{FBS}$ at $37{ }^{\circ} \mathrm{C}$ with $5 \% \mathrm{CO}_{2}$.

2. The cells are plated at a density of $10^{4}$ cells per well in $100 \mu l$ of appropriate complete growth medium without antibiotics in a 96-well, sterile microtiter plates.

3. For each well of cells, 6 pmol of siRNA (fluc-siRNA) is diluted into $25 \mu 1 \mathrm{RPMI}$ 1640 medium without serum in 96-well, sterile microtiter plates.

4. For each well of cells, appropriate amounts of the $N$-alkyl-PEI2k-IOs or $0.4 \mu \mathrm{l}$ Lipofectamine 2000 (Invitrogen) is diluted into $25 \mu$ l RPMI 1640 medium without serum and incubated for $5 \mathrm{~min}$ at room temperature.

5. The transfection agents from Step 4 are added to each well containing diluted siRNA from Step 3, mixed gently, and incubated at room temperature for $20 \mathrm{~min}$ to allow IO-siRNA complexes to form.

6. The IO-siRNA complexes $(50 \mu \mathrm{l})$ are added directly to each well of the plates containing cells and mixed gently.

7. The cells are incubated $\left(37^{\circ} \mathrm{C}, 5 \% \mathrm{CO}_{2}\right)$ for $3 \mathrm{~h}$ to allow the siRNA transfection.

8. The transfection medium is removed and the cells are cultured in fresh RPMI 1640 medium supplemented with $10 \% \mathrm{FBS}$ at $37{ }^{\circ} \mathrm{C}$ with $5 \% \mathrm{CO}_{2}$.

9. Forty-eight hours posttransfection, $20 \mu \mathrm{l}$ D-luciferin solution $(3 \mathrm{mg} / \mathrm{ml})$ is added into each well, and the cells are imaged in the plate using a Xenogen IVIS-100 system.

10. The imaging data are analyzed with Living Image v.3.1 software.

\subsection{Cytotoxicity assay}

1. After the IVIS imaging experiment, the medium is replaced with fresh serumenriched media, and $20 \mu \mathrm{l}$ MTT solution (3-(4,5-dimethylthiazol-2-yl)-2,5diphenyltetrazolium bromide, $5 \mathrm{mg} / \mathrm{ml}$ in PBS) is added into each well. The microplate is placed on a shaker ( $200 \mathrm{rpm}$ for $5 \mathrm{~min}$ ) to thoroughly mix the MTT into the media.

2. The cells are incubated $\left(37^{\circ} \mathrm{C}, 5 \% \mathrm{CO}_{2}\right)$ for $4 \mathrm{~h}$ to allow the MTT to be metabolized.

3. The culture media are removed.

4. Formazan (the MTT metabolic product) is resuspended in $200 \mu \mathrm{l}$ DMSO. The culture plate is placed on a shaker (200 rpm for $5 \mathrm{~min}$ ) to thoroughly mix the formazan into the solvent.

5. The optical density is read at $560 \mathrm{~nm}$ and the background at $670 \mathrm{~nm}$ is subtracted.

\subsection{MRI study of transfected cells}

1. After transfection as described above, the cells are washed three times using PBS with heparin sodium $(10 \mathrm{U} / \mathrm{ml})$ and the transfected cells are harvested.

2. The cells $\left(10^{6}\right)$ are suspended in $100 \mu 1$ agarose gel (2\%).

3. A $T_{2}$-weighted normal anatomic fast-spin echo MRI study is performed in a $7 \mathrm{~T}$ Bruker magnet (Bruker, Rheinstetten, Germany) with a 5-cm volume coil: 
$\mathrm{TR}=4200 \mathrm{~ms}, \mathrm{TE}=36.0 \mathrm{~ms}$, number of averages $=2, \mathrm{FOV}=30 \times 30 \mathrm{~mm}$, slice thickness $=1.0 \mathrm{~mm}$.

4. The $T_{2}$-weighted imaging is analyzed using NIH ImageJ (Bethesda, MD, USA).

\section{Notes}

1. In terms of size data between DLS and AFM, larger diameters of the IOs determined by AFM may be caused by the AFM tip broadening effect and particleflattening on the mica surface.

2. The N/P ratios can be calculated based on PEI nitrogen per nucleic acid phosphate $(1 \mu \mathrm{g}$ of siRNA has $3 \mathrm{nmol}$ of phosphate and $0.9 \mu \mathrm{g}$ PEI contains $10 \mathrm{nmol}$ of amine nitrogen).

3. The optimal incubation period for a maximal siRNA effect will need to be tested. Unnecessarily long incubation times may result in decreased transfection activity resulting from degradation.

4. Incubating the cells for a short time at $37^{\circ} \mathrm{C}$ before IVIS imaging can increase the signal.

5. Washing transfected cells with PBS with heparin sodium $(10 \mathrm{U} / \mathrm{ml})$ will help eliminate IOs from the extracellular surface.

6. Air can induce a hypointense signal on $T_{2}$-weighted sequences. To minimize any artifacts, the cells are placed gently into the agarose gel phantom to make sure no air is trapped.

7. MRI parameters should be optimized for different IO concentrations and magnetic field strengths.

\section{Anticipated Results}

The synthesized hydrophobic SPIO nanoparticles are monodisperse with a diameter of 12 nm (Fig. 13.1) (Wang et al., 2012). The structure of the SPIO nanoparticles characterized by high-resolution TEM and selected area electron diffraction indicates that the distance between two adjacent planes is $2.97 \AA$, corresponding to (220) planes in the spinelstructured $\mathrm{Fe}_{3} \mathrm{O}_{4}$.

Alkyl-PEI2k can transfer hydrophobic IOs from organic solvent to aqueous phase and hold multiple IOs with a controlled clustering structure, leading to higher $r_{2}$ values $(>300 \mathrm{Fe}$ $\mathrm{mM}^{-1} \mathrm{~s}^{-1}$ ) (Liu et al., 2011b). Both TEM and AFM analyses show that the hydrophilic nanocomposites are well dispersed without obvious aggregation (Fig. 13.2), and TEM studies also show that each nanocomposite is a cluster of a few closely packed SPIO nanoparticles (Fig. 13.2D).

The formed $\mathrm{N}$-alkyl-PEI2k-IO/siRNA complexes in pure water demonstrate an average hydrodynamic diameter of about $100 \mathrm{~nm}$ with relatively narrow distribution (Fig. 13.3) (Liu et al., 2011d). The zeta potentials of the complexes decrease when increasing the initial siRNA concentration (Fig. 13.3), suggesting successful loading of siRNA onto the nanoparticle surface.

The results of the retardation assay illustrate that the retardation efficiency increases with decreasing initial siRNA concentration (Fig. 13.4) (Liu et al., 2011d). The naked siRNA can be found to be released from $N$-alkyl-PEI2k-IO/siRNA complexes when heparin is added, presumably due to the stronger association of heparin with the particle surface than that of 
the siRNA (Fig. 13.4). $N$-alkyl-PEI2k-IO/siRNA complexes are obviously more stable than naked siRNA in the presence of serum, as shown in Fig. 13.4.

$N$-alkyl-PEI2k-IO/lucsiRNA complexes can induce silencing of specific genes of interest (Fig. 13.5) (Liu et al., 2011d). The improved gene-silencing effects of $N$-alkyl-PEI2k-IO/ lucsiRNA complexes may be due to an increased intracellular delivery, as physically stable siRNA polyelectrolyte complexes with a size around $100 \mathrm{~nm}$ are more readily internalized by cells through the endocytotic pathway. The $N$-alkyl-PEI2k-IO/siRNA complexes have no obvious cytotoxicity on 4T1-fluc cells under transfection conditions even at the highest concentration $(25 \mu \mathrm{g} \mathrm{Fe} / \mathrm{ml}$ ) (Liu et al., 2011d), which is fivefold higher than the concentration used in the cell transfection experiments, confirming that the gene silencing is a pure consequence of the RNAi effect.

At a $7 \mathrm{~T}$ magnetic field, the $N$-alkyl-PEI2k-IO/siRNA complex-transfected cells exhibit obviously decreased signal intensities on $T_{2}$-weighted images, and higher N/P ratios are associated with decreased signal intensities (Liu et al., 2011d). The internalized nanoparticles can shorten the spin-spin relaxation time by dephasing the spins of neighboring water protons, resulting in hypointensities on $T_{2}$-weighted images.

\section{Summary}

$N$-alkyl-PEI2k-IOs are synthesized using $N$-alkyl-PEI2k as the phase-transfer material, which bind siRNA and result in well-dispersed nanoparticles with uniform structure and narrow size distribution. Such $N$-alkyl-PEI2k-IOs have high siRNA binding capability, protecting siRNA from enzymatic degradation for effective siRNA delivery. With siRNA loading, $N$-alkyl-PEI2k-IOs induce enhanced luciferase gene (fluc) silencing in fluc-4T1 cells in cell culture with good biocompatibility. Meanwhile, the transfected cells display strong signal contrast compared to untreated cells on $T_{2}$-weighted MR imaging. This multifunctional nanocomposite system shows great potential for gene delivery with noninvasive imaging monitoring capability.

\section{Acknowledgments}

This work was supported by the Intramural Research Program (IRP) of the National Institutes of Biomedical Imaging and Bioengineering (NIBIB), National Institutes of Health (NIH), and the International Cooperative Program of National Science Foundation of China (NSFC) (81028009). The work was also supported by Projects of Sichuan Province (2011JQ0032, 2010SZ0294, and 09ZA036) and National Natural Science Foundation of China (20974065, 50603015, 51173117, and 81101101).

\section{References}

Arsianti M, Lim M, Marquis CP, Amal R. Assembly of polyethylenimine-based magnetic iron oxide vectors: Insights into gene delivery. Langmuir. 2010; 26:7314-7326. [PubMed: 20112951]

Boussif O, Lezoualc'h F, Zanta MA, Mergny MD, Scherman D, Demeneix B, Behr JP. A versatile vector for gene and oligonucleotide transfer into cells in culture and in vivo: Polyethylenimine. Proc Natl Acad Sci USA. 1995; 92:7297-7301. [PubMed: 7638184]

Cheong SJ, Lee CM, Kim SL, Jeong HJ, Kim EM, Park EH, Kim DW, Lim ST, Sohn MH. Superparamagnetic iron oxide nanoparticles-loaded chitosan-linoleic acid nanoparticles as an effective hepatocyte-targeted gene delivery system. Int J Pharm. 2009; 372:169-176. [PubMed: 19429277]

Demeneix B, Behr JP. Polyethylenimine (PEI). Adv Genet. 2005; 53:217-230. [PubMed: 16240995]

Godbey WT, Wu KK, Mikos AG. Poly(ethylenimine) and its role in gene delivery. J Control Release. 1999; 60:149-160. [PubMed: 10425321]

Hao R, Xing R, Xu Z, Hou Y, Gao S, Sun S. Synthesis, functionalization, and biomedical applications of multifunctional magnetic nanoparticles. Adv Mater. 2010; 22:2729-2742. [PubMed: 20473985] 
Hu C, Peng Q, Chen F, Zhong Z, Zhuo R. Low molecular weight polyethylenimine conjugated gold nanoparticles as efficient gene vectors. Bioconjug Chem. 2010; 21:836-843. [PubMed: 20438071]

Huang H, Yu H, Tang G, Wang Q, Li J. Low molecular weight polyethylenimine cross-linked by 2hydroxypropyl-gamma-cyclodextrin coupled to peptide targeting HER2 as a gene delivery vector. Biomaterials. 2010; 31:1830-1838. [PubMed: 19942284]

Kievit FM, Veiseh O, Bhattarai N, Fang C, Gunn JW, Lee D, Ellenbogen RG, Olson JM, Zhang M. PEI-PEG-Chitosan copolymer coated iron oxide nanoparticles for safe gene delivery: Synthesis, complexation, and transfection. Adv Funct Mater. 2009; 19:2244-2251. [PubMed: 20160995]

Liu G, Swierczewska M, Lee S, Chen X. Functional nanoparticles for molecular imaging guided gene delivery. Nano Today. 2010a; 5:524-539. [PubMed: 22473061]

Liu G, Swierczewska M, Niu G, Zhang X, Chen X. Molecular imaging of cell-based cancer immunotherapy. Mol Biosyst. 2011a; 7:993-1003. [PubMed: 21308113]

Liu G, Tian J, Liu C, Ai H, Gu Z, Gou J, Mo X. Cell labeling efficiency of layer-by-layer selfassembly modified silica nanoparticles. J Mater Res. 2009; 24:1317-1321.

Liu G, Wang Z, Lu J, Xia C, Gao F, Gong Q, Song B, Zhao X, Shuai X, Chen X, Ai H, Gu Z. Low molecular weight alkyl-polycation wrapped magnetite nanoparticle clusters as MRI probes for stem cell labeling and in vivo imaging. Biomaterials. 2011b; 32:528-537. [PubMed: 20869767]

Liu G, Xia C, Wang Z, Lv F, Gao F, Gong Q, Song B, Ai H, Gu Z. Magnetic resonance imaging probes for labeling of chondrocyte cells. J Mater Sci Mater Med. 2011c; 22:601-606. [PubMed: 21279674]

Liu G, Xie J, Zhang F, Wang Z, Luo K, Zhu L, Quan Q, Niu G, Lee S, Ai H, Chen X. N-alkyl-PEI functional iron oxide nanocluster for efficient siRNA delivery. Small. 2011d; 7:2742-2749. [PubMed: 21861295]

Liu G, Yang H, Zhang XM, Shao Y, Jiang H. MR imaging for the longevity of mesenchymal stem cells labeled with poly-L-lysine-resovist complexes. Contrast Media Mol Imaging. 2010b; 5:5358. [PubMed: 20235146]

Scherer F, Anton M, Schillinger U, Henke J, Bergemann C, Kruger A, Gansbacher B, Plank C. Magnetofection: Enhancing and targeting gene delivery by magnetic force in vitro and in vivo. Gene Ther. 2002; 9:102-109. [PubMed: 11857068]

Taratula O, Garbuzenko O, Savla R, Wang YA, He H, Minko T. Multifunctional nanomedicine platform for cancer specific delivery of siRNA by super-paramagnetic iron oxide nanoparticlesdendrimer complexes. Curr Drug Deliv. 2011; 8:59-69. [PubMed: 21034421]

Thomas M, Klibanov AM. Conjugation to gold nanoparticles enhances polyethylenimine's transfer of plasmid DNA into mammalian cells. Proc Natl Acad Sci USA. 2003; 100:9138-9143. [PubMed: 12886020]

Veiseh O, Kievit FM, Fang C, Mu N, Jana S, Leung MC, Mok H, Ellenbogen RG, Park JO, Zhang M. Chlorotoxin bound magnetic nanovector tailored for cancer cell targeting, imaging, and siRNA delivery. Biomaterials. 2010; 31:8032-8042. [PubMed: 20673683]

Wang Z, Liu G, Sun J, Gong Q, Song B, Sun S, Ai H, Gu Z. N-alkyl-polyethylenimine stabilized iron oxide nanoparticles as MRI visible transfection agents. J Nanosci Nanotechnol. 201210.1166/jnn. 2011.5151

Wang Z, Liu G, Sun J, Wu B, Gong Q, Song B, Ai H, Gu Z. Self-assembly of magnetite nanocrystals with amphiphilic polyethylenimine: Structures and applications in magnetic resonance imaging. $J$ Nanosci Nanotechnol. 2009; 9:378-385. [PubMed: 19441322]

Xie J, Liu G, Eden HS, Ai H, Chen X. Surface-engineered magnetic nanoparticle platforms for cancer imaging and therapy. Acc Chem Res. 2011; 44:883-892. [PubMed: 21548618] 

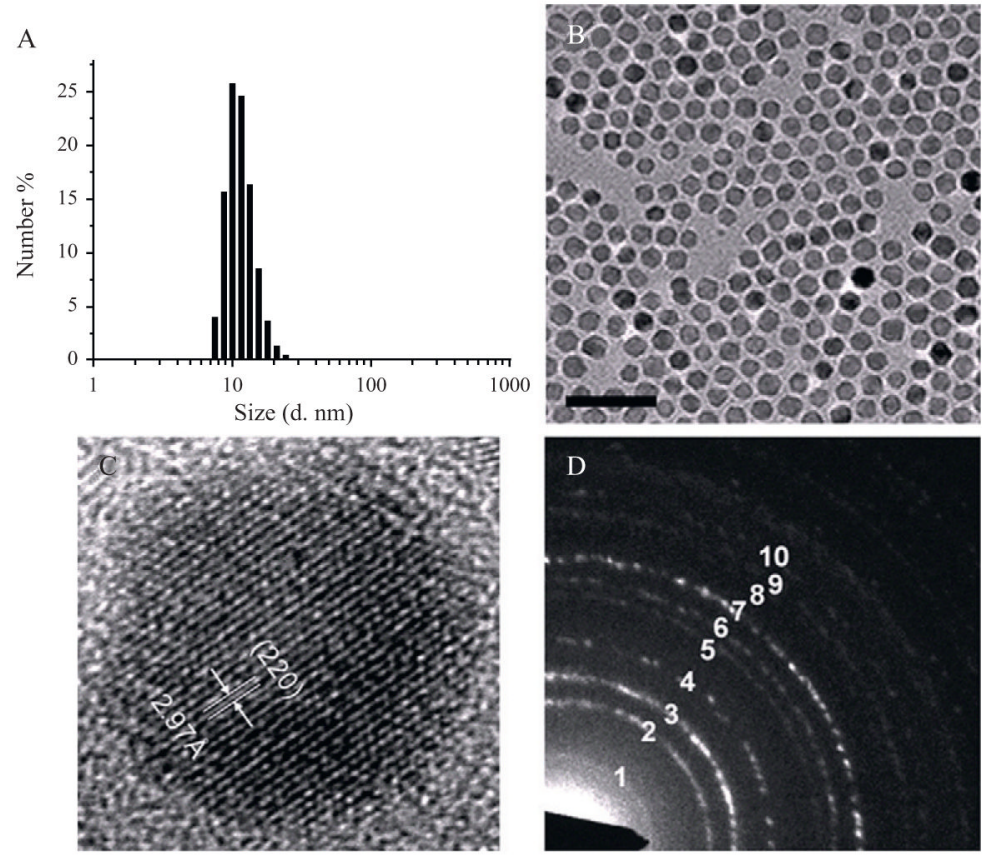

D

\begin{tabular}{cccccc}
\hline Ring & $d(\AA)$ & $\mathrm{Fe}_{3} \mathrm{O}_{4}$ & $h$ & $k$ & $l$ \\
\hline 1 & 4.86 & 4.86 & 1 & 1 & 1 \\
2 & 2.98 & 2.97 & 2 & 2 & 0 \\
3 & 2.54 & 2.53 & 3 & 1 & 1 \\
4 & 2.13 & 2.10 & 4 & 0 & 0 \\
5 & 1.73 & 1.71 & 4 & 2 & 2 \\
6 & 1.63 & 1.62 & 5 & 1 & 1 \\
7 & 1.50 & 1.48 & 4 & 4 & 0 \\
8 & 1.34 & 1.33 & 6 & 2 & 0 \\
9 & 1.30 & 1.28 & 5 & 3 & 3 \\
10 & 1.23 & 1.21 & 4 & 4 & 4
\end{tabular}

Figure 13.1.

(A) DLS and (B) TEM images of magnetite nanoparticles in hexane; (C) measured lattice spacing, $d(\AA)$, based on the rings in (D) and standard atomic spacing for $\mathrm{Fe}_{3} \mathrm{O}_{4}$ along with their respective Miller indexes from the PDF database (from Wang et al., 2012). 
A
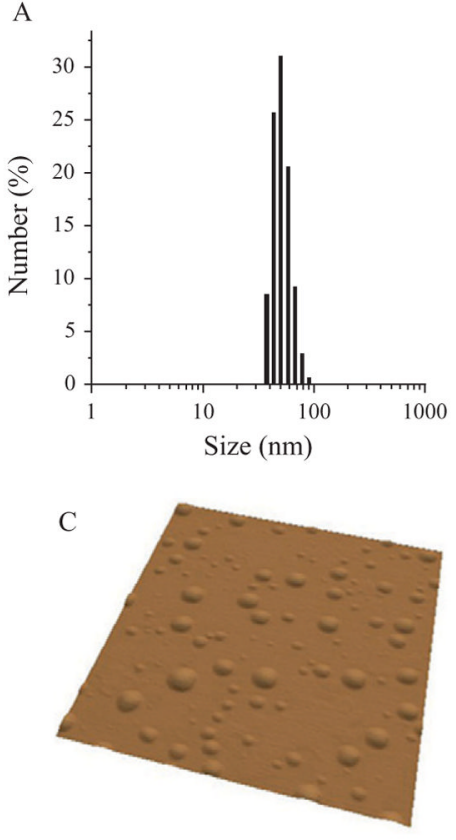

B
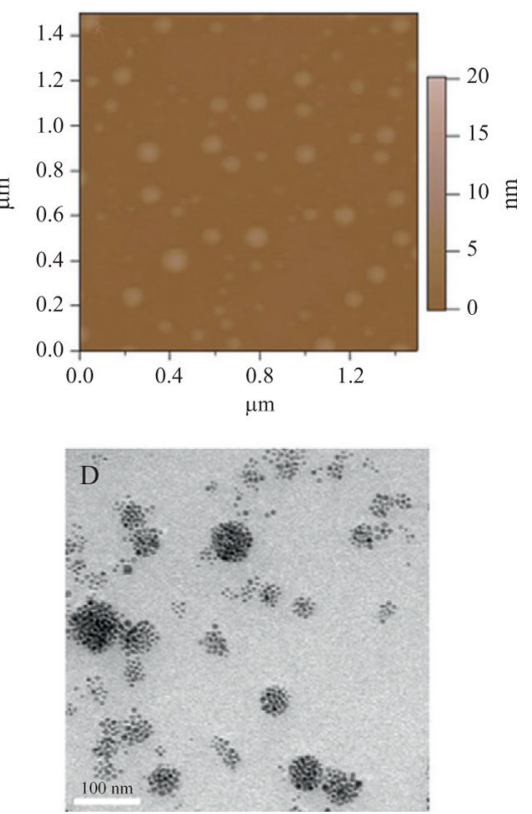

Figure 13.2.

Physical characterization of $N$-alkyl-PEI2k-IOs. DLS (A), AFM height image (B), 3D AFM image (C) of the same area in (B) and TEM image (D) of SPIO nanoparticle clusters (from Liu et al., 2011b). 
A

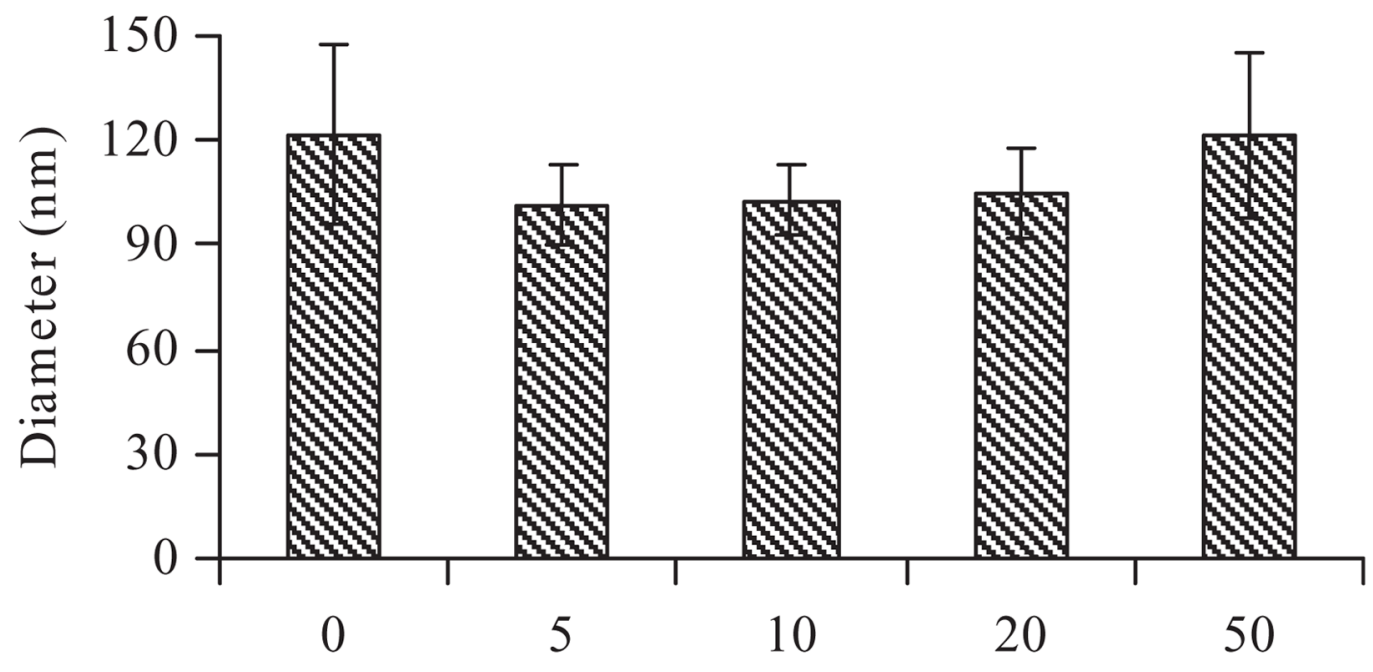

$\mathrm{B}$

$\mathrm{N} / \mathrm{P}$ ratio

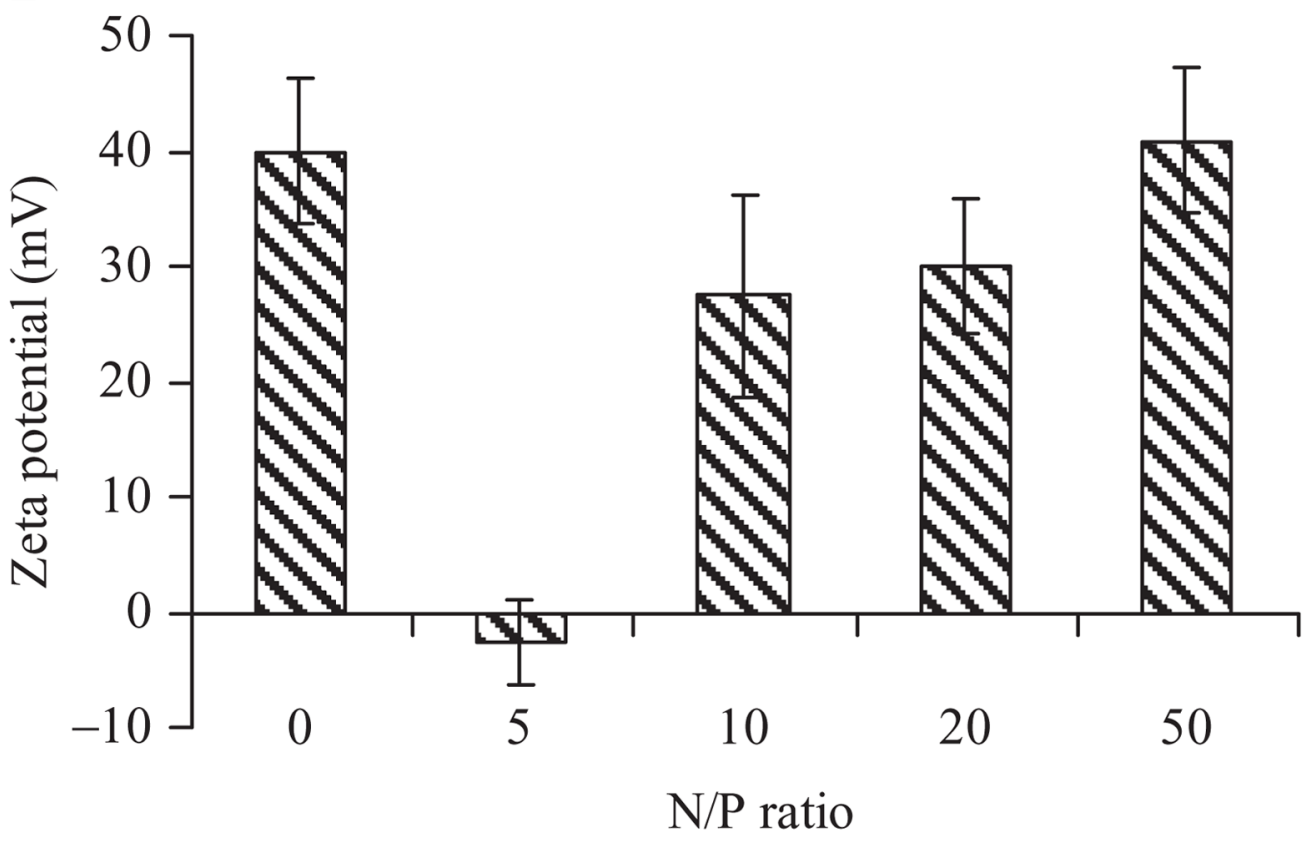

Figure 13.3.

Physical characterization of $N$-alkyl-PEI2k-IO/siRNA complexes. (A) Average diameter and (B) zeta potential of $N$-alkyl-PEI2k-IO/siRNA complexes at various $\mathrm{N} / \mathrm{P}$ ratios (from Liu et al., 2011d). 

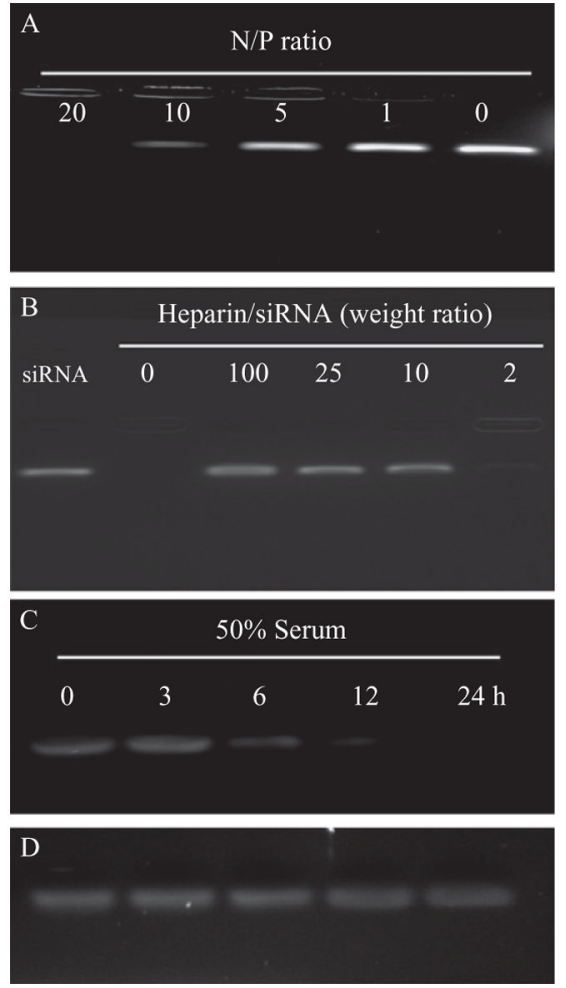

Figure 13.4.

Agarose gel electrophoresis of $N$-alkyl-PEI2k-IO/siRNA complexes: (A) electrophoretic retardation analysis of siRNA binding with $N$-alkyl-PEI2k-IOs/siRNA samples; (B) release of siRNA with the addition of heparin at various concentrations; (C, D) serum stability of siRNA when complexed with $\mathrm{N}$-alkyl-PEI2k-IOs at an N/P ratio of 20 . The study was performed in $50 \%$ serum solution for a predetermined incubation time (from Liu et al., 2011d). 


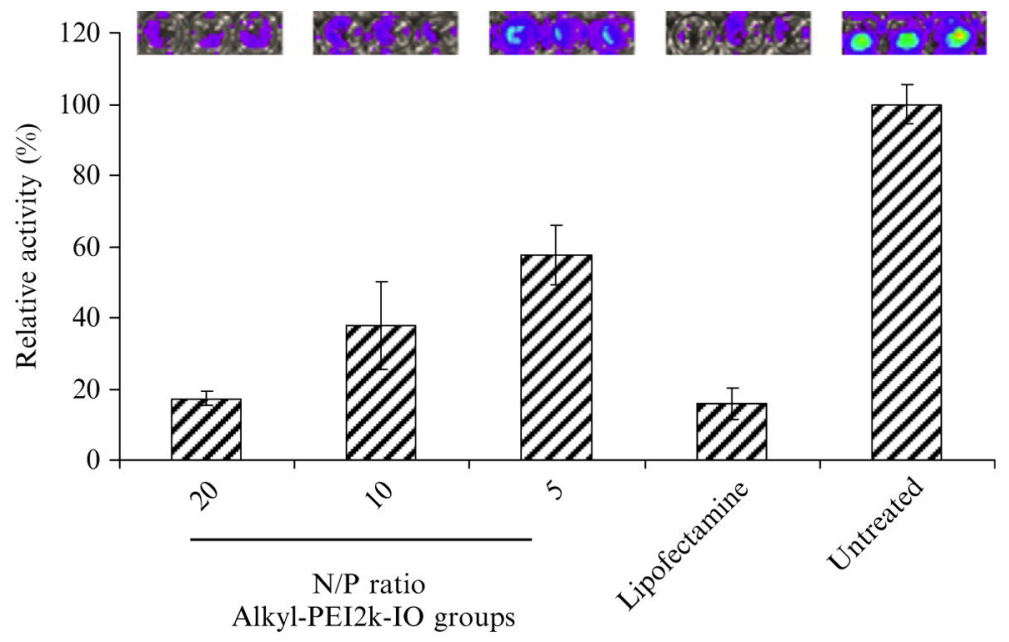

Figure 13.5.

Inhibition of fluc gene expression by $N$-alkyl-PEI2k-IOs/siRNA (siRNA=6 pmol) at various $\mathrm{N} / \mathrm{P}$ ratios. 